\title{
The Performance Of Undiversified Portfolio In Indonesia Stock Exchange
}

Budi Frensidy, Universitas Indonesia, Jakarta, Indonesia

\begin{abstract}
This research is aimed to analyze the diversification practice among domestic retail investors at the Indonesia Stock Exchange (IDX) and its portfolio performance. An individual domestic investor at IDX holds 4.3 stocks on average with the median two stocks. This is far from the minimum number of stocks required for the diversification purpose. But, this finding is in line with the findings of Goetzmann \& Kumar (2008), Kelly (1995), and Polkovnichenko (2005). For the performance, without considering risk, minimum diversification with five stocks or fewer and moderate diversification with six to ten stocks in the portfolios tend to be better than the extensive diversification. However, when risk is taken into account, the undiversified portfolios do not outperform the extensive diversification.
\end{abstract}

Keywords: Undiversified Portfolio; Retail Investor; Diversification Practice; Portfolio Performance

\section{INTRODUCTION}

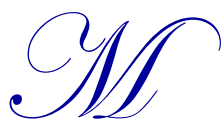

odern portfolio theory which was started by Markowitz (1952) teaches investors to diversify in order to minimize risk. Diversification will lower portfolio risk at a given expected return or raise expected return at a given risk.

Theoretically, most investors know the diversification benefits in reducing the risk. In practice, however, many investors do not apply the diversification theory. Research about the practice of retail investors in Indonesia Stock Exchange (IDX) has never been done in Indonesia or any emerging country. In Indonesia, this study is important as the number of retail investors by November 2011 accounts $95.4 \%$ of all investors (197,885 retail investors of total 203,689 investors) and most of them are domestic investors.

Another interesting issue concerning the diversification practice to be found out is whether the performance of the undiversified portfolios outdoes the diversified portfolios. Theoretically, it is expected that undiversified portfolios will underperform the well-diversified portfolios and the market.

Unlike the research by Goetzmann \& Kumar (2008) and Mitton \& Vorkink (2007), to measure performance, this research uses the category variables for the number of stocks held by retail investors. They are minimum diversification for 1-5 stocks, moderate diversification for 6 to 10 stocks, and extensive diversification for more than ten stocks. By this grouping, we will get the optimal range of the number of stocks that can generate the highest return in the sample in two measures of return, nominal return and risk-adjusted return. The study to measure the performance of retail investors in different levels of diversifications has never been done before whether in Indonesia or worldwide, so this study is expected to open further research on the performance of retail investors especially in Indonesia.

\section{LITERATURE REVIEW}

Research to find out the optimal number of stocks to get the optimal benefits of diversification was done for the first time by Evans and Archer (1968). They find that there is very little benefit when the portfolio already has eight to ten stocks with the same weight, even if the diversification is done randomly. Fisher and Lorie (1970) and Jacob (1970) support Evan and Archer's findings. Elton and Gruber (1977) continued the research and found almost similar results that most of the diversification gain which is the total risk reduction up to 51 percent is already 
achieved when the number of securities reaches ten. The portfolio risk decreases another 5 percent when the number of stocks is 20 and additional 2 percent when the number becomes 30 . There is no significant decline when there are 50 stocks or more.

Another study done by Bloomfield, Leftwich, and Long (1977) found that it required at least 20 stocks to obtain the benefits of an equity portfolio. Last, Statman (1987) got different result that not fewer than 30 stocks are needed to reap the optimal benefits of diversification. The number of stocks should be increased as long as the marginal benefit (risk reduction) is higher than the marginal cost (transaction cost).

Based on the above studies, it can be concluded that a well-diversified portfolio is one that consists of at least more than ten stocks. This practice is common among institutional investors and fund managers who run mutual funds as they may hold maximum 10 percent for any single stock. However, it is not the case with the retail or individual investors who have five stocks or fewer in their portfolios (Goetzmann and Kumar, 2008).

The study on the underdiversification practice of the retail investors has begun since Blume and Friend (1975) found that $34.1 \%$ of a sample of 17,056 American investors, each holds only one dividend-paying stock, $50 \%$ had two stocks, and only $10.7 \%$ investors collected more than 10 stocks. The Survey of Reserve Board in the United States in 1975 finds the same results that the average of stock holding among retail investors is 3.41. Lease, Lewellen, and Schlarbaum (1976), King \& Leape (1998), and Starr-McCluer (1995) support the above findings that most retail investors (70\%) do not diversify.

Kelly (1995) confirms the same phenomenon of underdiversification that out of 632 stock investors, only 35 hold ten or more stocks, and only 11 have twenty or more stocks. Diversification cost is definitely not the reason as $75 \%$ investors whose portfolios are in the top $20 \%$ have less than ten stocks. The median of stock holding is one and it becomes two if the investors who own stocks of their own company are excluded from the sample. Another study of Barber and Odean (2000) in the United States for the period January 1991 to December 1996 captures similar phenomenon. From a sample of 78,000 stock investors, Barber and Odean report that the median of stocks owned is between 2 and 3 with the mean of 4 stocks.

Polkovnichenko's study (2005) gets almost identical results that the number of stocks retail investors have is only two in 1983 and increases to three in 1991. During that period, about $80 \%$ investors have five stocks or fewer and $90 \%$ own fewer than 10 stocks. Besides that, $40 \%$ possess only one stock in their portfolios. Seven percent of the households hold the stocks of the companies where they work. Goetzmann and Kumar (2008) also report that 25$33 \%$ of investors' portfolios contain only one stock and more than 55\% consist of three or fewer stocks. This pattern happens along the observation period (1991-1996) although there is an increase in the average number of stocks held by the investors from four to seven stocks. Only $5-12 \%$ of the portfolios comprise more than ten stocks.

In Germany, retail stock investors also do not diversify (Dorn and Huberman, 2010). Of 20,000 accounts in a big securities company in the period 1995-2000, investors on average collect around three stocks.

On one hand, there is a problem with the diversification practice among the retail investors in the United States and Germany. On the other hand, there is another more important issue than this underdiversification practice namely whether the underdiversified portfolios could generate higher return. Does diversification always give a better payoff? If it does and it is proven significantly, retail investors are recommended to directly buy index funds.

There are two different findings about this. Goetzmann and Kumar (2008) find the undiversified portfolios always give lower risk-adjusted return in 1991-1996. The Sharpe ratios for the portfolios with two stocks is only 0.34 and increase to 0.56 when the number of stocks becomes fifteen or more. Dorn and Huberman (2010) with their preferred habitat hypothesis say that investors who do not diversify get lower Sharpe ratios because they face higher nonsystematic risk. Similar findings are given by Kumar (2009) and Hoffmann \& Shefrin (2011) that there is no evidence the return is positively related to the risk faced.

Mitton and Vorkink (2007) to some extent support the above results that the risk-adjusted return of undiversified portfolios is lower than that of the diversified one. However, the skewness of the undiversified portfolios is also 
significantly different from the diversified one. The implication is, for the investment holding period of six months, Mitton and Vorkink (2007) find, the odds of underdiversified portfolios (to the diversified one) to be the best $1 \%$ performance is 11 to 1 . For the holding period of three years, the odds become 26 to 1 . In line with its upside return potential, the downside risk for the undiversified portfolio to be in the worst $1 \%$ performance is also bigger. In other words, Mitton and Vorkink (2007) in their sample find that the returns of undiversified have a very wide range.

The most interesting findings about portfolios with 2-3 stocks are given by Barber and Odean (2000). They observe the percentage of investors who do not diversify in outperforming the market namely beating the market return (S \& P 500 index). About $49.3 \%$ of the investors surveyed beat the market before taking transaction costs into account and $43.4 \%$ after considering the transaction costs. Even though we realize that the market return is the average return and that $50 \%$ investors can get return above this average, knowing that retail investors with 2-3 stocks could beat the market is beyond expectation. However, Barber and Odean (2000) also warn that the annual return of the undiversified portfolios could vary a lot from $-95 \%$ to more than $11,000 \%$. They conclude that failure to diversify, done intentionally or unintentionally, could result better return.

\section{DATA AND METHODOLOGY}

The analysis unit in this research is domestic retail investor namely those investors who have an account in securities company using an Indonesian ID card. The sample is taken from the Indonesian Central Securities Depository or Kustodian Sentral Efek Indonesia (KSEI). The secondary data of the transactions done in the last 34 months by 910 domestic retail investors (ending January 2009 until beginning December 2011) and the monthly portfolio balance during the observation period are used for each investor selected.

The data are needed to assess the diversification level chosen and the performance achieved. Two measures for the performance are used namely nominal return and Sharpe ratio (for the risk-adjusted return) for three levels of diversification: minimum, moderate, and extensive diversification.

The data used in this study is $0.46 \%$ of the population recorded by KSEI on November 30, 2011. The percentage is better than, but not much different from, the sample in Mitton \& Vorkink (2007) with 0.13\%, Goetzmann \& Kumar (2008) with $0.01 \%$, and Dorn \& Huberman (2010) in Germany with $0.23 \%$. Kelly (1995) even used only 632 retail investors for his sample.

$$
\begin{aligned}
& \mathrm{ri}=\beta 0+\beta 1 \mathrm{D} 1 \mathrm{i}+\beta 2 \mathrm{D} 2 \mathrm{i}+\beta 3 \text { Sizei }+\beta 4 \text { Turnoveri }+\varepsilon \mathrm{i} \\
& \mathrm{rS}=\gamma 0+\gamma 1 \mathrm{D} 1 \mathrm{i}+\gamma 2 \mathrm{D} 2 \mathrm{i}+\gamma 3 \text { Sizei }+\gamma 4 \text { Turnoveri }+\varepsilon \mathrm{i}
\end{aligned}
$$

where:

D1 is minimum diversification (1-5 stocks)

D2 is moderate diversification (6-10 stocks)

ri is average monthly nominal return (arithmetic)

$\mathrm{rS}$ is average monthly Sharpe ratio namely (ri - rf)/ $/ \mathrm{i}$

Size is $\ln$ of average portfolio size of the retail investor

Turnover is the average turnover of the investor's portfolio

In this research, the performances of minimum and moderate diversification are measured and compared to that of the extensive diversification. Sharpe ratio is used as a proxy for the risk-adjusted return. Understanding that KSEI does not record the transaction costs that vary among the securities companies, the return used in this study is the return before transaction costs. 


\section{RESULTS AND DISCUSSION}

Table 1. Descriptive statistics

\begin{tabular}{|c|c|c|c|c|c|}
\hline Variable & Observation & Mean & $\begin{array}{c}\text { Standard } \\
\text { Deviation }\end{array}$ & Minimum & Maximum \\
\hline $\mathrm{Ri}$ & 910 & .0342 & .0201 & -.0306 & .1078 \\
\hline $\mathrm{RS}$ & 910 & .1945 & .1323 & -.27 & .95 \\
\hline Size & 910 & 18.1295 & 1.5519 & 15.55 & 23.43 \\
\hline Turnover & 910 & .7900 & 1.0817 & 0 & 9.5683 \\
\hline \multicolumn{6}{|c|}{ D1 = 1 (Minimum Diversification) } \\
\hline $\mathrm{Ri}$ & 581 & .0343 & .0221 & -.0306 & .1078 \\
\hline $\mathrm{RS}$ & 581 & .1785 & .1354 & -.27 & .52 \\
\hline Size & 581 & 17.5869 & 1.3441 & 15.62 & 23.1 \\
\hline Turnover & 581 & .7857 & 1.1894 & 0 & 10.38 \\
\hline \multicolumn{6}{|c|}{ D2 $=1$ (Moderate Diversification) } \\
\hline $\mathrm{Ri}$ & 213 & .0359 & .0166 & -.0159 & .0795 \\
\hline $\mathrm{RS}$ & 213 & .2188 & .1162 & -.15 & .67 \\
\hline Size & 213 & 18.7993 & 1.3516 & 15.55 & 22.76 \\
\hline Turnover & 213 & .8578 & .9224 & 0 & 5.79 \\
\hline \multicolumn{6}{|c|}{$\mathrm{D} 1=\mathrm{D} 2=0$ (Extensive Diversification) } \\
\hline $\mathrm{Ri}$ & 116 & .0306 & .0144 & -.0142 & .0990 \\
\hline $\mathrm{RS}$ & 116 & .2303 & .1315 & -.15 & .95 \\
\hline Size & 116 & 19.6175 & 1.4161 & 16.03 & 23.43 \\
\hline Turnover & 116 & .6871 & .7201 & 0 & 3.54 \\
\hline
\end{tabular}

The monthly return obtained by retail investors for 34 months from January 2009 to November 2011 is $3.43 \%$ with a standard deviation of $2.01 \%$. The composite index of Indonesia Stock Exchange (IDX) or IHSG rises $178.77 \%$ for the observation period (from 1,333 on January 31, 2009 to 3,715 on November 30,2011) or $3.06 \%$ on a monthly basis. Whereas the monthly Sharpe ratio for the same period is 0.19 with a standard deviation of 0.13 . About 581 retail investors $(63.9 \%)$ choose to hold up to five stocks (minimum diversification), 213 (23.4\%) do the moderate diversification with six to ten stocks in their portfolios, and only $116(12.7 \%)$ diversify extensively.

Compared to the population parameters, these results are not much different as the mean and median of stocks held by all retail investors in Indonesia Stock Exchange (IDX) are 4.34 and 2 stocks by the end of 2011. These findings are consistent with those of Goetzmann \& Kumar (2008), Kelly (1995), and Polkovnichenko (2005).

The lowest and highest monthly return of the sample, namely $-3.06 \%$ and $10.78 \%$ are experienced by the portfolio with minimum diversification. Whereas the lowest average monthly return belongs to those with the extensive diversification and the highest average return is for the investors with moderate diversification. Some retail investors who chase high returns could obtain the expected returns, while some others should be willing to accept below-themarket return or even experience losses.

For the Sharpe ratio, the lowest average (0.18) and the minimum (-0.27) ratio are experienced by the portfolios with minimum diversification. While the highest average Sharpe ratio $(0.23)$ and the highest Sharpe ratio (0.95) belong to the investors with extensive diversification. Based on the risk, minimum diversification gives the highest risk, seen from its Sharpe ratio or its volatility. This is consistent with the findings of Dorn \& Huberman (2010) and Goetzmann \& Kumar (2008) that investors who do not diversify face higher risk than those who diversify. This shows the tradeoff between risk and return. Investors who chase high return also face high risk or high return, high risk.

\subsection{Nominal Return}

Before estimating the parameters of the model using Stata 11, the classical assumptions in the ordinary least square are tested. For the multicollinearity assumption, VIF test is used; and for the heteroscedasticity, Breusch-Pagan test 
is adopted. After making sure that there are no multicollinearity and heteroscedasticity problems with the data, model estimation is run to get the following result.

Table 2. Regression result for nominal return

\begin{tabular}{|c|c|c|c|c|}
\hline \multicolumn{5}{|l|}{ Panel A: } \\
\hline \multicolumn{2}{|l|}{ Source } & SS & Df & MS \\
\hline \multirow{2}{*}{\multicolumn{2}{|c|}{$\begin{array}{l}\text { Model } \\
\text { Residual }\end{array}$}} & .006784522 & 4 & .001696131 \\
\hline & & .361571618 & 905 & .000399527 \\
\hline \multicolumn{2}{|l|}{ Total } & .36835614 & 909 & .000405232 \\
\hline \multicolumn{5}{|l|}{ Panel B: } \\
\hline \multicolumn{2}{|l|}{$r_{i}$} & Coefficient & $\mathbf{Z}$ & $\mathbf{P}>|\mathbf{z}|$ \\
\hline \multicolumn{2}{|l|}{ Div1 } & .0067814 & 2.99 & $0.001 * * *$ \\
\hline \multicolumn{2}{|l|}{ Div2 } & .0064962 & 2.77 & $0.003 * * *$ \\
\hline \multicolumn{2}{|l|}{ Size } & .0015535 & 3.17 & $0.001 * * *$ \\
\hline \multicolumn{2}{|l|}{ Turnover } & .0006476 & 1.05 & 0.146 \\
\hline \multicolumn{2}{|l|}{ Constant } & -.0003385 & -0.03 & 0.486 \\
\hline \multicolumn{5}{|c|}{ Number of obs $=910$} \\
\hline $\mathrm{F}(4,905)$ & \multicolumn{4}{|l|}{$=4.25$} \\
\hline Prob $>F$ & \multicolumn{4}{|l|}{$=0.0021$} \\
\hline R-squared & \multicolumn{4}{|l|}{$=0.0184$} \\
\hline Root MSE & \multicolumn{4}{|l|}{$=0.01999$} \\
\hline
\end{tabular}

The estimated model becomes:

$$
r_{i}^{\Lambda}=-0.03 \%+0.68 \% \text { Div1 }+0.65 \% \text { Div2 }+0.155 \% \text { Size }+0.065 \% \text { Turnover }
$$

where $r_{i}=$ the average of monthly nominal return

For the overall model, p-value is 0.0021 ; so the coefficients altogether can be used for the model. Based on the regression result, the two coefficients of the hypothesis variables are significant at $\alpha=1 \%$. So is one of the two control variables (portfolio size).

For the coefficient test (t-test), it can be concluded that the portfolios of minimum and moderate diversification in the research sample have higher monthly nominal return than that of extensive diversification. The additional monthly return for the minimum and moderate diversification is $0.68 \%$ and $0.65 \%$ respectively. Both are significant at $\alpha=1 \%$. This higher monthly return is likely to come from the investors' competence in stock selection. Another plausible explanation is, by focusing only on few stocks, retail investors could really understand the stocks they collect and do the timing in buying and selling them (Oneil, 2002).

Even though the incremental return for the investors doing the minimum diversification is higher than those choosing the moderate diversification, the average return of the portfolios in the moderate diversification is the highest. This is due to the fact that the average portfolio size of moderate diversification is bigger than the minimum diversification; and size is positively related to the return. The average monthly return of portfolios with moderate diversification is $3.59 \%$ while that with minimum diversification is $3.43 \%$.

The monthly return that is obtained by investors with minimum and moderate diversification outperforms not only those with extensive diversification but also the market return which both grew 3,06\% monthly for the same period. What is also striking from the descriptive statistics is we document the monthly return of a well-diversified portfolio is equal to the market return. The higher return of undiversified portfolios in this study is in line with the findings of Mitton and Vorkink (2007). In pursuing higher return, underdiversified investors select stocks that have substantially higher average skewness than stocks most often selected by diversified investors Mitton and Vorkink (2007). 
On the contrary, Goetzmann dan Kumar (2008) find the opposite results. They report undiversified investor on average gets lower return than the diversified investors. Nevertheless, the portfolios with high turnover in the minimum diversification could give high return, better than the portfolios in the extensive diversification in their research. Goetzmann dan Kumar (2008) presumed this group of investors had the advantages in the information or in the better investment skills.

One control variable is significant and has the expected sign. The portfolio size is positively related to the nominal return. Investors who have big money have more flexibility, access, and capacity in picking stocks that they can have a better result.

\subsection{Risk-Adjusted Return}

The monthly return for investors' performance used in 4.1 has one drawback namely it has not considered risk involved. As we know, risk and return are two sides of a coin. When risk is taken into account, we have Sharpe ratio that is used in the study of Goetzmann \& Kumar (2008) and Mitton \& Vorkink (2007). Sharpe ratio that measures the excess return per unit total risk has its strength as it combines both return and risk into one ratio. This ratio is derived by dividing the excess return $\left(r_{i}\right)$ over risk-free rate $\left(r_{f}\right)$ by standard deviation or $\left(r_{i}-r_{f}\right) / \sigma_{i}$.

Therefore, for another alternative of return, Sharpe ratio is used in this study to measure the performance of undiversified portfolios compared to the diversified one. Like the nominal return, before estimating the coefficient for Sharpe ratio, multicollinearity and heteroscedasticity assumptions are examined using VIF test and BreuschPagan test.

The final estimation after the above tests and treatment is as follows:

Table 3. Regression Result For Sharpe Ratio

\begin{tabular}{l|c|c|c}
\hline \multicolumn{1}{c|}{ Sharpe Ratio } & Coefficient & $\mathbf{z}$ & $\mathbf{P}>|\mathbf{z}|$ \\
\hline Div1 & -.0297055 & -1.91 & $0.028^{* *}$ \\
\hline Div2 & -.000921 & -0.06 & 0.426 \\
\hline Size & .0102897 & 3.29 & $0.001^{* * *}$ \\
\hline Turnover & -.0122491 & -3.33 & $0.001^{* * *}$ \\
\hline Constant & .0368172 & 0.57 & 0.285 \\
\hline Number of obs $=910$ & & & \\
\hline F $(4,905)$ & & & \\
\hline Root MSE & $=0.11 .78$ & & \\
\hline R-squared & $=0.0460$ & & \\
\hline Prob $>$ F & $=0.0000$ & &
\end{tabular}

The estimated model for Sharpe ratio becomes:

$$
r_{S i}^{\Lambda}=0.037-0.030 \mathrm{Div} 1-0.001 \mathrm{Div} 2+0.010 \text { Size }-0.012 \text { Turnover }
$$

where $r_{S i}=$ Sharpe ratio

For F-test, the overall model can be used because $\mathrm{p}$-value $=0,0000$. For t-test, two coefficients of control variables and one hypothesis variable are significant at $\alpha=1 \%$.

Using one of the risk-adjusted returns, the performance of minimum diversification was, in fact, worse than that of extensive diversification. On average, the monthly Sharpe ratio of minimum diversification was 0.03 lower than that of the extensive diversification for the years 2009-2011. These findings are significant at $\alpha=5 \%$.

This means, although the monthly nominal return of portfolios in the minimum diversification is higher than that of extensive diversification, the risk faced by such portfolios is much higher than the excess return given. This is in line with the findings of Dorn \& Huberman (2010), Goetzmann \& Kumar (2008), and Latane \& Young (1969) that the performance of extensive diversification, if viewed in terms of mean-variance, is still better. 
Behind the better nominal return, retail stock investors who do not diversify should be ready to face the high risk of return fluctuation that makes their Sharpe ratio lower.

For the moderate diversification, there is no enough evidence from the research sample that this level of diversification has lower risk-adjusted return than that of extensive diversification. This confirms the view of Evans \& Archer (1968), Fisher \& Lorie (1970), Jacob (1974), and Elton \& Gruber (1977) that most of the diversification benefits i.e. risk reduction have been obtained when the number of stocks has reached eight to ten stocks.

For the control variables portfolio size and turnover, both are significant at $\alpha=1 \%$. Sharpe ratio is expected to rise as the size of portfolio goes up. Investor with bigger fund has more flexibility and better access to earn higher return per unit risk than the investor with limited money. These findings are in harmony with the study of Goetzmann and Kumar (2008) and contrary to the research results of Barber and Odean (2000) with higher risk-adjusted return for smaller portfolios.

The relationship of portfolio turnover and return is negative. Retail stock investors who trade more frequently are believed to have lower Sharpe ratio. Retail stock investors who are very active in trading think that they have better information and skill than other investors. In fact, they have neither the superior skill that is needed nor the valuable insider information. This negative relationship is consistent with the results of Barber \& Odean (2000) that trading is hazardous to the portfolio return and of Goetzmann \& Kumar (2008) as well.

\section{CONCLUSION}

Most retail investors in the Indonesia Stock Exchange do not diversify. They have on average only 4-5 stocks with the median 2 stocks in their portfolios. Based on the performance, retail investors choosing minimum and moderate diversification significantly obtain higher nominal return than those of the extensive diversification. Anyway, using the Sharpe ratio, the additional return is not enough to compensate the much higher risk faced by the underdiversification.

The additional monthly return of minimum and moderate diversification over that of extensive diversification in the sample is on average $0.68 \%$ and $0.65 \%$ respectively. For the Sharpe ratio, the return that is obtained by portfolio with minimum diversification is 0.03 lower than that of extensive diversification. The additional risk faced by investors applying minimum diversification is much bigger than the extra return they can get so their Sharpe ratio becomes smaller.

The findings that the undiversified portfolios could give higher nominal return and lower Sharpe ratio than the diversified portfolio in this study is consistent with Mitton and Vorkink (2007).

\section{AUTHOR BIOGRAPHY}

Dr. Budi Frensidy is currently a senior lecturer of finance and capital market in his alma mater and a regular columnist for two national prestigious newspapers in Indonesia. He has written more than 500 articles for his columns. He is also one of the directors in the Indonesian Financial Management Association (IFMA).

\section{REFERENCES}

Barber, Brad dan Terrance Odean. Trading Is Hazardous to Your Wealth: The Common Stock Investment Performance of Individual Investors. Journal of Finance, 55, 773-806. 2000.

Bloomfield, Ted, Richard Leftwich, and John Long. Portfolio Strategies and Performance. Journal of Financial Economics, 5, 202-218. 1977.

Blume, Marshall dan Irwin Friend. The Asset Structure of Individual Portfolios and Some Implications for Utility Functions. Journal of Finance, 30, 585-603. 1975.

Dorn, Daniel dan Gur Huberman. Preferred Risk Habitat of Individual Investors. Journal of Financial Economics, 97, $155-173$. 2010.

Elton, E. dan M. Gruber. Risk Reduction and Portfolio Size: An Analytical Solution. Journal of Business, 50, 415-426. 1977. 
Evans J.L. dan S.H. Archer. Diversification and the Reduction of Dispersion: An Empirical Analysis. Journal of Finance, 23, 761-767. 1968.

Fisher, K.L. dan Lorie J.H. Some Studies on Variability of Returns on Investments on Common Stocks. Journal of Business, 43 , 99-134. 1970.

Goetzmann, William dan Alok Kumar. Equity Portfolio Diversification. Review of Finance, 12, 433-463. 2008.

Hoffmann, A. dan H. Shefrin. Online Investors: What They Want, What They Do, and How Their Portfolio Perform. Working Paper, Maastricht University. 2011.

Jacob, N.L. A Limited Diversification Portfolio Selection Model for the Small Investor. Journal of Finance, 29, 837-857. 1974.

Kelly, Morgan. All Their Eggs in One Basket: Portfolio Diversification of US Households. Journal of Economics Behavior and Organization, 27, 87-96. 1995.

King, M. dan J. L. Leape. Wealth and Portfolio Composition: Theory and Evidence. Journal of Public Economics, 69, 155-193. 1998.

Kumar, Alok. Who Gambles in the Stock Market. Journal of Finance, 64, 1889-1933. 2009.

Latané, Harvey A. dan William E. Young. Test of Portfolio Building Rules. Journal of Finance, XXIV, 595-612. 1969.

Lease, R. C. W. Lewellen, dan G. Schlarbaum. Market Segmentation: Evidence on the Individual Investor. Financial Analysts Journal, 32, 53-60. 1976.

Markowitz, Harry. Portfolio Selection. Journal of Finance, 7, 77-91. 1952.

Mitton, Todd and Keith Vorkink. Equilibrium Underdiversification and the Preference for Skewness. Review of Financial Studies, 20 (4), 1255-1288. 2007.

Oneil, William J. How to Make Money in Stocks: A Winning System in Good or Bad Times, 3rd ed. McGraw-Hill. 2002.

Polkovnichenko, V. Household Portfolio Diversification: A Case for Rank Dependent Preferences. Review of Financial Studies, 18, 1467-1501. 2005.

Starr-McCluer, Martha. Tax Losses and the Stock Portfolios of Individual Investors. Working Paper, Federal Reserve Board of Governors, Washington, D. C. 1995.

Statman, Meir. How Many Stocks Make a Diversified Portfolio? Journal of Financial and Quantitative Analysis, 22, $353-363$. 1987. 